EXEMPLARIa Classica

Journal of Classical Philology

18, 2014, pp. 5-21

ISSN 1699-3225

\title{
LOS RELATOS DE MENSA JERO Y LA PROBLEMATIZACIÓN DE LA VISIÓN EN BACANTES DE EURÍPIDES ${ }^{1}$
}

\author{
M. Carmen Encinas Reguero \\ Universidad del País Vasco / Euskal Herriko Unibertsitatea \\ mcarmenencinas@gmail.com
}

\section{SUMMARY}

In Bacchae Euripides includes deliberately two messenger-speeches, whose structure and content are parallel. In that situation the differences between both speeches acquire a special meaning. Those differences affect especially how the view of the facts is presented. That leads to complex questions related to perception of reality.

KEYWORDS

Greek tragedy, Euripides, Bacchae, messenger-speech.

\section{RESUMEN}

En Bacantes Eurípides elabora conscientemente dos relatos de mensajero con una estructura y un contenido paralelos. En esa situación las diferencias entre ambos relatos cobran un especial significado. Esas diferencias afectan de manera especial al modo en que se presenta la visión de los hechos. Todo ello conduce a cuestiones de mayor calado relacionadas con la percepción de la realidad.

Palabras Clave

Tragedia griega, Eurípides, Bacantes, relato de mensajero.

Fecha de recepción: 15/11/2013

Fecha de aceptación y versión final: 15/02/2014

Aunque no es lo más habitual, en algunas de sus últimas tragedias, como Ifigenia entre los tauros, Fenicias, Orestes y Bacantes, Eurípides decide incluir dos largos relatos de mensajero ${ }^{2}$, concediendo con ello un protagonismo

${ }^{1}$ Este trabajo ha sido elaborado en el marco de un proyecto de investigación financiado por el Ministerio de Economía y Competitividad (FFI2012-34030) y de otro financiado por la UPV/EHU (EHU12/15). Además, se ha llevado a cabo dentro del Grupo Consolidado del Gobierno Vasco IT760-13. Así mismo, agradezco a la Dra. M. Quijada (Universidad del País Vasco) la ayuda que me ha prestado con la atenta lectura de este trabajo y sus sugerencias al respecto. Y agradezco también a los evaluadores anónimos de la revista sus correcciones y valiosos comentarios.

2 Cf. R. P. Winnington-Ingram, "Euripides: Poiêtês Sophos", Arethusa 2.2, 1969, 134: "Second messengers are not avoided, but their speeches tend to be short; the full-scale 
muy importante a la narración, pero corriendo el riesgo también de provocar una cierta monotonía ${ }^{3}$. Para evitarlo, Eurípides recurre a diversas técnicas: en Ifigenia entre los tauros los dos relatos se separan todo lo posible (el primero ocupa los vv. 260-339 y el segundo, los vv. 1327-419)4; en Orestes el segundo relato de mensajero (vv. 1395-502) queda convertido en una monodia ${ }^{5}$; en Fenicias los dos relatos de mensajero están divididos en dos partes para evitar la larguísima narración. Además, el primer relato (vv. 1090-199 y 1217-63) se centra en la batalla global de argivos y tebanos y anuncia el enfrentamiento individual entre Eteocles y Polinices, y el segundo relato (vv. 1356-424 y 1427-79) narra el enfrentamiento particular entre Eteocles y Polinices y las consecuencias del mismo.

Pero en Bacantes ${ }^{6}$ curiosamente Eurípides no trata de separar los dos relatos de mensajero o de diferenciarlos de alguna manera, sino que hace precisamente todo lo contrario, pues los dos principales relatos de mensajero de este drama (vv. 677-774 y 1043-152) ${ }^{7}$ están cercanos entre sí y, sobre todo, ofrecen una estructura paralela ${ }^{8}$ y un contenido que, aunque diferente, se sitúa en los dos casos en un marco idéntico, una visita al Citerón, y ofrece notables paralelismos.

messenger-speeches are rare”. No obstante, la tendencia de Eurípides a incluir dos relatos de mensajero en algunos de sus últimos dramas ha sido señalada en muchas ocasiones. Para J. M. Marcos Pérez, "El relato del mensajero en Eurípides: concepto y estructura", Minerva 8, 1994, 79 , casi todas esas obras "se caracterizan por la diversidad dramático-novelesca de su acción". Se puede encontrar un inventario de los discursos de mensajero en Eurípides en I. J. F. de Jong, Narrative in Drama. The Art of the Euripidean Messenger-Speech, Leiden 1991, 179-82.

${ }^{3}$ No sólo Eurípides, también Sófocles incluye dos relatos de mensajero en algunas de sus tragedias. Es el caso de Antígona y también de Traquinias, donde la narración ostenta un llamativo protagonismo. Sobre la narración en Traquinias, cf. M. C. Encinas Reguero, "Forma dramática y problemas de comunicación y conocimiento en Traquinias y Edipo Rey", Minerva 19, 2006, sobre todo 11-2.

${ }^{4}$ Cf. Winnington-Ingram, "Euripides", 141 n. 52.

${ }^{5}$ Sobre los relatos de mensajero en Orestes, cf. M. C. Encinas Reguero, "El relato de mensajero en el Orestes de Eurípides", Emerita 79.1, 2011, 131-54, M. C. Encinas Reguero, "La estructura del Orestes de Eurípides y el enigmático relato del frigio”, $C F C(G) 21,2011,119-33$.

${ }^{6}$ E. R. Dodds, Euripides. Bacchae, Oxford 1944, xxxiii-xxxiv, considera que en Bacantes es el hecho de que la obra tiene que ver con lo milagroso lo que impone un uso amplio de la narración. Según Dodds, el poeta sitúa un milagro psicológico en el centro de la acción, pero los milagros físicos han de ser narrados forzosamente.

7 Estos dos relatos de mensajero son los principales, pero no los únicos en Bacantes. A ellos cabe añadir el relato del sirviente, que anuncia el apresamiento del extranjero-Dioniso y la liberación de las bacantes antes capturadas (vv. 434-50), e incluso el relato del extranjeroDioniso en la escena del 'milagro del palacio' (vv. 616-41).

${ }^{8}$ Cf. Winnington-Ingram, "Euripides", 141 n. 52. Por su parte, Jong, Narrative in Drama, 122 , considera que los dos relatos de mensajero de Bacantes se pueden ver como un par de 'mirror-scenes', del tipo de las estudiadas por O. Taplin, Greek Tragedy in Action, London 1978, 122-39. En otro lugar esta misma autora (I. J. F. de Jong, "Récit et Drame: le deuxième récit de messager dans Les Bacchantes”, REG 105, 1992, 574) considera el primer relato de mensajero como un espejo para Penteo, porque sirve para advertirle, y para los espectadores, porque anticipa el segundo relato de mensajero. 
Lejos de ser un error técnico de un dramaturgo que estaba ya en el final de su carrera y había dado muestras sobradas de una gran maestría compositiva, se trata, sin duda, de una estructura buscada por él con un fin determinado. Es, por lo tanto, del mayor interés intentar definir cuál es el objetivo que persigue Eurípides con dicha duplicidad 9 .

Para ello se va a poner de relieve en lo que sigue, primero, la estructura paralela que ambos relatos de mensajero exhiben y, a continuación, algunas diferencias significativas que se dan entre ellos ${ }^{10}$. Esas diferencias afectan fundamentalmente al modo en que se presenta la percepción de los hechos que se narran por parte de los diferentes personajes implicados, que mantienen posturas diferentes con respecto al dios. Como se verá, Penteo carece de visión y niega al dios, el mensajero puede ver y acepta a Dioniso y las bacantes tienen una visión deformada en consonancia con su sometimiento a la divinidad ${ }^{11}$.

\section{ESTRUCTURA DE LOS DISCURSOS}

Los dos principales discursos de mensajero de Bacantes (vv. 677-774 y 1043-152) poseen una estructura casi idéntica. Ambos comienzan con una breve introducción, en la que el narrador se sitúa con respecto a los hechos que va a narrar. A ésta le sigue la narración propiamente dicha, que se divide básicamente en tres apartados ${ }^{12}$, a saber, 1) una descripción de las bacantes en estado relajado; 2) la exposición de un hecho que cambia esa situación; y 3) la descripción de las bacantes furiosas y de sus acciones ${ }^{13}$. Tras estos hechos se describe el regreso de las bacantes, ya sea a la situación inicial en el Citerón, en el primer relato de mensajero, ya sea a la ciudad, en el segundo. Y, por último, se sitúa el

\footnotetext{
${ }^{9}$ Que una misma realidad esté presentada de manera doble no es excepcional en Bacantes; muy al contrario, se trata de un patrón que se repite obstinadamente a lo largo de toda la obra. Al respecto, cf. C. Segal, Dionysiac Poetics and Euripides'Bacchae, New Jersey 1982, 27-31, S. Goldhill, "Doubling and Recognition in the Bacchae", Metis 3, 1988, 137-56.

${ }^{10} \mathrm{La}$ conveniencia de comparar ambos relatos ya fue advertida, por ejemplo, por R. G. A. Buxton, "The Messenger and the Maenads: a Speech from Euripides' Bacchae (10431152)”, AantHung 32, 1989, 233-4, aunque este autor no lleva la comparación muy lejos. Posteriormente, R. G. A. Buxton, "News from Cithaeron: Narrators and Narratives in the Bacchae", Pallas 37, 1991, 39-48, defiende la conveniencia de analizar estos dos relatos de mensajero como elementos finales de una serie narrativa que abarca también el discurso programático de Dioniso (vv. 23-42), los versos iniciales de Penteo (vv. 215-25) y el relato del primer sirviente (vv. 434-50).

${ }^{11}$ Utilizo para Bacantes la edición de Dodds, Euripides. Bacchae, que reproduce el texto y aparato crítico de G. Murray, Euripides, Oxford 1913², así como la traducción de C. García Gual, L. A. de Cuenca y Prado, Eurípides. Tragedias III, Madrid 1979 (reimpr. 1985).

${ }^{12}$ Sobre la estructura tripartita de los dos relatos de mensajero, cf. G. Erdmann, Der Botenbericht bei Euripides. Struktur und dramatische Funktion, Diss. Kiel 1964, 160-6. La división de Erdmann, sin embargo, no coincide plenamente con la propuesta en este trabajo.

${ }^{13}$ R. P. Winnington-Ingram, Euripides and Dionysus. An Interpretation of the Bacchae, London $1997^{2}\left(1948^{1}\right), 72$, considera la yuxtaposición del dios sonriente y de su milagro en la rhesis del sirviente (vv. 434-50) como un precedente de las escenas de paz y violencia que describen los mensajeros.
} 
comentario personal del mensajero, que reconoce la divinidad de Dioniso, en el primer relato, y la superioridad de los dioses en general, en el segundo.

Esta similitud que se advierte en el patrón general, se mantiene incluso en la subdivisión que se puede hacer dentro de cada una de las tres partes que conforman la narración.

La primera de esas partes es, como ha quedado dicho, la descripción de las bacantes en estado relajado. Esta parte se subdivide en ambos relatos en otras dos, a saber, la descripción idílica de las bacantes y la descripción de algún hecho milagroso. Ambos elementos se presentan, no obstante, de manera distinta. Así, en el primer relato la descripción idílica de las bacantes las muestra en reposo, mientras que en el segundo las muestra ocupadas "en placenteras

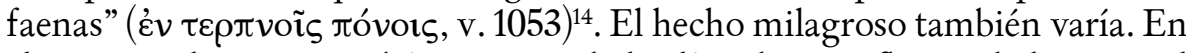
el primer relato se trata básicamente de los líquidos que fluyen de la tierra al simple golpe de los tirsos de las bacantes; en el segundo, del curvamiento de un alto abeto para permitir a Penteo subirse a él. En los dos casos el milagro tiene su origen en Dioniso ${ }^{15}$ y se relaciona con elementos de la naturaleza.

El segundo apartado de la narración se centra en el hecho concreto que altera radicalmente el estado de las bacantes. En el primer relato se trata de un hecho de orden humano: uno de los pastores propone atrapar a Ágave y el resto lo secunda y pone en marcha el plan. No solo es un hecho de orden humano, sino en cierto modo también político, ya que se dice que quien propone el plan es un hombre que participa en las instituciones de la polis con asiduidad (v. 717) y que su objetivo es granjearse el favor del monarca (v. 721) ${ }^{16}$. Por otra parte, la presentación de los hechos se hace en dos pasos: primero se introduce la propuesta y después se describe la puesta en marcha del plan.

En el segundo relato de mensajero el hecho que produce el cambio es de orden divino, pues se trata de la voz de Dioniso, que impulsa a las bacantes a emprender la acción. Este elemento se presenta también en dos pasos, ya que la primera orden del dios no es entendida inicialmente por las bacantes y ha de ser repetida una segunda vez ${ }^{17}$.

${ }^{14} \mathrm{La}$ descripción de las bacantes las presenta en todo momento de manera ordenada. Se

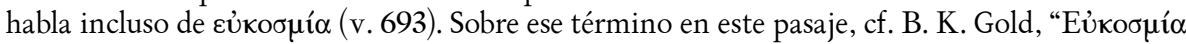
in Euripides' Bacchae", AJPh 98, 1977, 3-15.

${ }^{15}$ El milagro tiene su origen en Dioniso en los dos relatos de mensajero, pero afecta a seres diferentes: las bacantes y Penteo. Ambos son aparentemente seguidores del dios, pero realmente lo son solo a la fuerza. A ambos Dioniso les concede aparentemente un beneficio, pero éste se muestra a la postre realmente como un castigo.

${ }^{16}$ Según D. Susanetti, Euripide. Baccanti, Roma 2010, 233-4, la propuesta de tender una emboscada a las bacantes es impía. Por tanto, "Il male dell'irreligiosità e la logica dell'opportunismo sono così implicitamente associati ancora una volta alla retorica e al cuore della piazza cittadina”.

${ }^{17}$ Se han visto tras los hechos descritos en la segunda rhesis de mensajero todos los pasos propios del rito del sacrificio en Grecia; cf. B. Seidensticker, "Sacrificial Ritual in the Bacchae", en G. W. Bowersock, W. Burkert, M. C. J.Putnam, eds., Arktouros. Hellenic Studies presented 
Por último, la narración termina con la descripción de las bacantes furiosas y de sus acciones. Esta parte también se subdivide en dos, a saber, el sparagmos y el ataque. El orden, sin embargo, está invertido. En el primer relato se describe inicialmente el sparagmos de las reses y después el ataque a los poblados. En el segundo se describe en primer lugar el ataque a Penteo y después su sparagmos ${ }^{18}$. En los dos casos el ataque afecta al orden cívico, en un caso porque se atacan poblados, en el otro porque se ataca a Penteo, que es el rey de Tebas. Pero, además, el ataque al orden cívico implica una subversión aún más profunda del orden establecido. En el primer relato, porque las mujeres atacan a hombres y niños; en el segundo, porque una madre ataca a su hijo. En definitiva, en ambos casos, porque mujeres y madres atacan a los niños o jóvenes en lugar de protegerlos.

A pesar del paralelismo, entre ambos relatos se da un paso de lo general a lo particular, pues se pasa de una locura que conduce a la destrucción de la población en general, a una locura que lleva a la destrucción de la propia familia y del propio linaje ${ }^{19}$.

Así pues, aunque la estructura paralela de ambas rheseis es innegable, esa estructura conlleva unas diferencias, cuyo análisis puede ayudar a determinar mejor las intenciones del autor.

\section{El MENSAJERo y PENTEO: SU VISIÓN DE LOS HeChos}

Según las convenciones del género trágico, el mensajero, que entra en escena para narrar lo que ha visto a quien no lo ha visto, necesita establecer su autoridad respecto a la información que proporciona y para ello establece,

to Bernard M.W. Knox on the occasion of his $65^{\text {th }}$ Birthday, Berlin-New York 1979, 18190. En concreto, la orden de Dioniso seguida del silencio se corresponde con el ritual típico del sacrificio; cf. ibid., 184-6, H. P. Foley, Ritual Irony. Poetry and Sacrifice in Euripides, Ithaca-London 1985, 208-11. Sobre el sacrificio dionisíaco, cf. M. Daraki, “Aspects du sacrifice dionysiaque”, Revue de l'histoire des religions 197, 1980, 131-57. Además, en otros momentos de la tragedia se hallan presentes también otros rituales esenciales en la polis griega. Así, por ejemplo, en la exodos se encuentra el lamento propio de la madre por el hijo y el epitaphios logos de Cadmo hacia su nieto. Ambos elementos, no obstante, aparecen distorsionados; cf. C. Segal, "Female Mourning and Dionysiac Lament in Euripides' Bacchae", en A. Bierl, P. von Möllenforff, eds. (en colaboración con S. Vogt), Orchestra. Drama, Mythos, Bühne. Festschrift für Hellmut Flashar anläßlich seines 65. Geburtstages, Stuttgart-Leipzig 1994, 16-7 y C. Segal, "Chorus and Community in Euripides' Bacchae", en L. Edmunds, R. W. Wallace, eds., Poet, Public, and Performance in Ancient Greece, Baltimore-London 1997, 76-85. Además, el regreso de Ágave se describe en términos de una victoria atlética (v. 1147); cf. Winnington-Ingram, Euripides and Dionysus, 24-5, Foley, Ritual Irony, 212-4.

${ }^{18}$ Erdmann, Der Botenbericht bei Euripides, 166, habla de ironía trágica en su más alto grado porque Penteo muere víctima del mismo tipo de ataque que le fue narrado en el primer relato de mensajero.

${ }^{19}$ Precisamente la familia y el hogar, el yévos y el oĩkos, son los ejes básicos en torno a los cuales gira la vida de la mujer en Grecia. Con su acción, por lo tanto, las bacantes atentan contra su propia esencia. 
generalmente al principio de la rhesis y a través de un verbo de 'ver' (habitualmente óó́co o zĩ $\delta o v)^{20}$, su cualidad de testigo presencial de los hechos que va a narrar ${ }^{21}$.

Pues bien, en el primer relato de mensajero de Bacantes la apelación a la visión directa de los hechos no se halla solo al comienzo de la rhesis, sino que se repite en varias ocasiones a lo largo de la misma, mostrando una insistencia llamativa. En concreto, y dentro de la estructura expuesta anteriormente, las referencias a la visión se sitúan en la parte primera y última de la narración, que rodean al suceso central, que es el que produce un cambio en la actitud de las bacantes; y dentro de esas dos partes señaladas, además, en cada uno de sus dos subapartados.

Ahora bien, existe una diferencia entre la apelación inicial a la visión directa de los hechos y el resto de referencias a ella. El mensajero utiliza

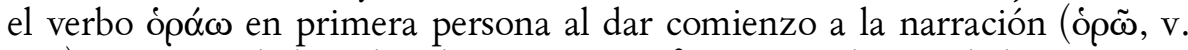

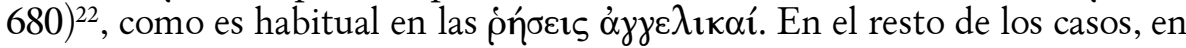
cambio, el establecimiento de la cualidad de testigo presencial del mensajero se da de forma indirecta. En varias ocasiones el mensajero utiliza un infinitivo para enfatizar lo que supone poder ver a las bacantes (cf. v. 693:

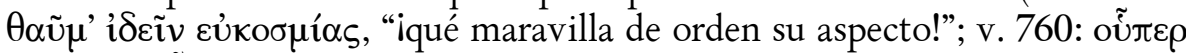

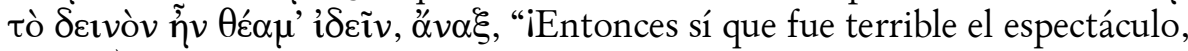
señor!”). Implícitamente se puede entender que estas expresiones subrayan la condición de testigo presencial del mensajero, aunque ello no se afirme explícitamente mediante una primera persona verbal. Algo similar sucede en el resto de los casos, en los que el mensajero se refiere a la hipotética visión de Penteo, que, de haber estado allí presente, habría podido ver lo mismo

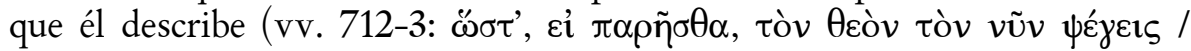

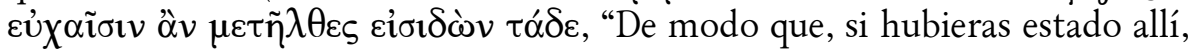
habrías ido con oraciones al encuentro del dios al que ahora censuras, a la

${ }^{20}$ Jong, Narrative in Drama, 183-4, proporciona un listado con las expresiones que los mensajeros utilizan en Eurípides para remarcar su cualidad de testigos presenciales.

${ }^{21}$ Respecto al mensajero como testigo presencial, cf. Jong, Narrative in Drama, 1-62. Ahora bien, la visión es un tema esencial en toda la tragedia de Bacantes y no solo en sus relatos de mensajero; cf. J.-P. Vernant, "El Dioniso enmascarado de las Bacantes de Eurípides", en J.-P. Vernant, P. Vidal-Naquet, Mito y tragedia en la Grecia antigua, Madrid 1989, 25865, J. L. Navarro González, "Visión y audición en la tragedia griega: complejidad escénica de Las Bacantes", Iter 4, 1995, 209-25, C. Thumiger, "Visione e identità nelle Baccanti di Euripide", ACME 60.2, 2007, 3-29, I. Rizzini, "Le Baccanti o l'ossessione della visione", en A. Beltrametti, ed., Studi e materiali per le Baccanti di Euripide, Pavia 2007, 107-62. Continuamente en la obra se llama la atención sobre lo que se ve, sugiriendo un paralelismo entre los personajes del drama y los espectadores, $\theta \varepsilon \alpha \tau \alpha i ́$ de un espectáculo trágico; cf. J. Pórtulas, "La máscara del sufriente. Acerca de las Bacantes", en J. A. López Férez, ed., La tragedia griega en sus textos. Forma (lengua, estilo, métrica, crítica textual) y contenido (pensamiento, mitos, intertextualidad), Madrid 2004, 361-4.

${ }^{22}$ El mensajero afirma explícitamente su visión de los hechos incluso en el diálogo que

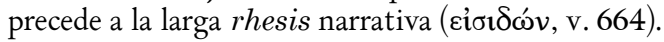




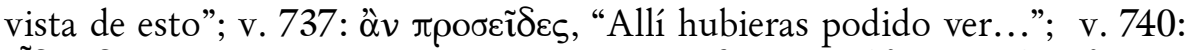

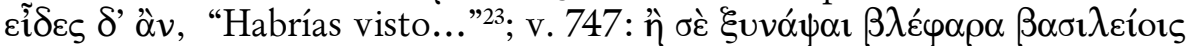
кópaıs, “...de lo que podrías captar con tus regias pupilas”). Implícitamente se ha de entender que con estas expresiones el mensajero está afirmando de forma indirecta su propia visión de los hechos. Pero, además, esta alusión a la visión de Penteo tiene un efecto irónico, porque el soberano emprenderá poco después el camino hacia el Citerón para ver personalmente a las bacantes (hechos que describe el segundo relato de mensajero), pero su visión no podrá hacerse efectiva ${ }^{24}$.

Así pues, la condición de testigo presencial del mensajero en este primer relato queda, según parece, sólidamente establecida, pero, además, en el relato se apunta también a la importancia de la visión de Penteo, un tema que se desarrolla en el segundo relato de mensajero.

Efectivamente, el segundo relato comienza describiendo el inicio de la expedición y a sus miembros -Penteo, el extranjero y el propio mensajero-,

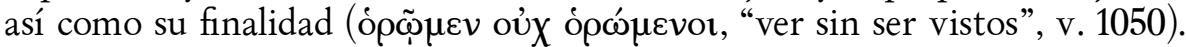
A partir de ahí empieza la narración con la descripción de las bacantes ${ }^{25}$. Este punto sería el lugar más adecuado para que el mensajero, dadas las convenciones dramáticas, dejase constancia de su visión directa de los hechos, como sucede en el primer relato (ò $\tilde{\omega}$, v. 680). Sin embargo, aquí eso no se hace. Lo que sí hace el mensajero, sin embargo, es marcar al final de esta descripción de las

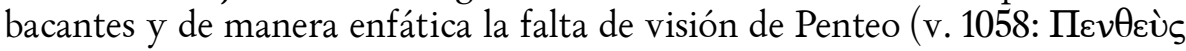

${ }^{23}$ En este punto me distancio de la traducción utilizada (cf. nota 11), que propone "Se podía ver..." sin reflejar la segunda persona y el modo irreal utilizados en el texto griego.

${ }^{24}$ Este tipo de alusiones a la visión potencial del receptor se puede encontrar también en otros discursos de mensajero, pero en ningún caso con tanta profusión como en este pasaje de Bacantes; cf. Jong, Narrative in Drama, 105.

${ }^{25}$ Adviértase que la situación del mensajero con respecto a los hechos narrados es muy diferente en cada rhesis. El primer mensajero dice que es al subir una cima cuando se le hacen visibles las bacantes (vv. 677-9). Así pues, él está en un lugar alto y las bacantes, a igual nivel o inferior, no están muy lejos. Más adelante, después del sparagmos, las mujeres se lanzan al ataque contra Hisias y Eritras, poblaciones enclavadas "al pie de la ladera del Citerón" (vv.

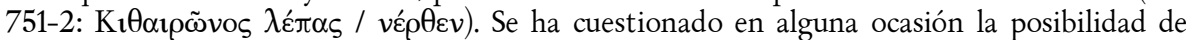
que el mensajero vea realmente lo que sucede en esos lugares (cf. J. Barrett, "Pentheus and the Spectator in Euripides' Bacchae", AJPh 119, 1998, 347-8, J. Barrett, Staged Narrative. Poetics and the Messenger in Greek Tragedy, Berkeley-Los Angeles-Londres 2002, 11820 ), pero quizás ha de entenderse que lo ve desde la distancia gracias a su posición elevada. Esa posición elevada, desde la que se contempla lo que sucede en un lugar inferior, es similar a la que mantienen los espectadores en el teatro con respecto a lo que sucede en escena, lo que puede conducir a reflexiones de índole metateatral, muchas veces apuntadas en relación a esta obra. En el segundo relato de mensajero la situación inicial es exactamente la contraria. El mensajero y sus acompañantes no llegan a una cima, desde donde ven, sino que entran "por la falda del

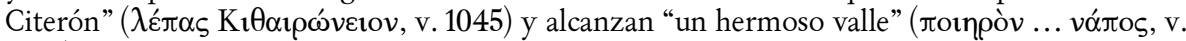
1048), desde donde pretenden ver sin ser vistos. Todos los hechos descritos se desarrollan en un lugar bajo y es la audiencia del teatro únicamente la que ocupa una posición elevada desde la que contemplar la escena. 
$\delta^{\prime}$ ò $\tau \lambda \eta \dot{n} \mu \omega v \theta \tilde{\eta} \lambda u v$ oủx ò $\rho \tilde{\omega} v$ óx $\lambda o v$, "Penteo, el desdichado, que no veía el tropel de mujeres"; vv. 1060-2 [en un discurso directo atribuido al propio

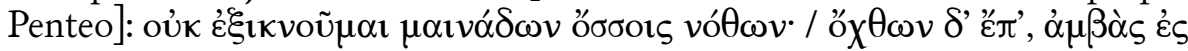

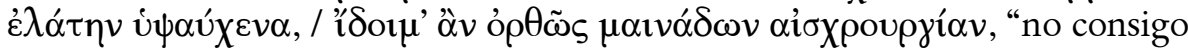
ver con mis ojos a esas bastardas ménades. Pero si me subiera a un picacho o a un árbol de alto cuello, seguramente vería bien la vergonzosa actitud de las ménades"). Esto es irónico por varios motivos. En primer lugar, porque Penteo, aun sin poder ver a las ménades, se refiere a su "vergonzosa actitud" ( $\alpha i \sigma x \rho o v \rho i^{\alpha} \alpha v$, v. 1062), lo que contrasta fuertemente con la descripción ofrecida por el mensajero en los versos inmediatamente anteriores (vv. 10517 ), donde las ménades han sido presentadas de un modo idílico ${ }^{26}$. En segundo lugar, las palabras de Penteo resultan irónicas porque el primer mensajero había resaltado insistentemente lo que Penteo podría ver si fuese al Citerón y sucede que, cuando el joven va a ese lugar, no puede ver nada.

La paradoja, además, es que Penteo y el mensajero están juntos, como se ha dejado claro en la introducción (vv. 1045-7), así que es difícil comprender que uno de ellos pueda ver y el otro no. La crítica se ha inclinado a entender que el mensajero ve realmente y que Penteo no lo hace porque no es capaz de asumir lo que tiene ante los ojos, que se opone a sus ideas preconcebidas ${ }^{27}$. Ahora bien, la realidad es que el texto dice explícitamente que Penteo no ve y en ningún lugar de este pasaje se afirma que el mensajero sí lo hace ${ }^{28}$. Es cierto que la descripción detallada de las bacantes y el hecho de estar ante un relato de mensajero, en el que por convención se exponen hechos presenciados y en el que se ha dicho de forma explícita que la finalidad es ver (v. 1050), conduce a pensar que el mensajero es testigo visual. Pero la realidad es que el texto no lo dice de manera expresa, a pesar de que con ello se opone a la convención y, además, a la situación paralela del primer relato de mensajero.

La primera vez que este segundo mensajero utiliza un verbo de 'ver' en primera persona del singular lo hace un poco más adelante, pero para afirmar la visión de un hecho que se desarrolla junto a él y no en el escenario distanciado en el que se encuentran las bacantes, que es el lugar sobre cuya

${ }^{26}$ Este pasaje no es el único momento de Bacantes en que los mismos hechos son presenciados por dos personajes distintos y entendidos de manera absolutamente dispar. La escena que mejor ejemplifica esa situación es probablemente la controvertida escena del 'milagro del palacio'. Al respecto véase M. C. Encinas Reguero, “Bacantes de Eurípides. El 'milagro del palacio' y su funcionalidad dramática”, REA 114.2, 2012, 405-22.

${ }^{27}$ Cf., por ejemplo, J. A. LaRue, "Prurience Uncovered: the Psychology of Euripides' Pentheus", CJ 63, 1968, 214, Buxton, “The Messenger and the Maenads”, 228-9, WinningtonIngram, Euripides and Dionysus, 128-9.

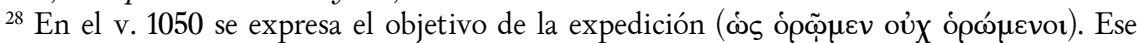
verbo de 'ver' en primera persona del plural no afirma una visión de facto en el momento de la narración y, por tanto, no es válido para establecer la cualidad de testigos presenciales de quienes forman parte de la expedición al Citerón. De hecho, si así fuera, implicaría también la visión de Penteo. 
visibilidad se pueden tener dudas. Además, es curioso que lo primero que el mensajero ve es precisamente un hecho sobrenatural ( $\theta \alpha \tilde{u} \mu$ ' ó $\rho \tilde{\omega}$, v. 1063), concretamente el del árbol que se curva ${ }^{29}$. Sin embargo, ya escenas anteriores de la tragedia, sobre todo la escena del 'milagro del palacio' (vv. 576-641), han dejado claro que la apreciación de un $\theta \alpha \tilde{u} \mu \alpha$ es algo subjetivo ${ }^{30}$. Con esos precedentes, que este mensajero diga que ve un $\theta \alpha \tilde{u} \mu \alpha$ lleva a preguntarse qué es lo que ve realmente el mensajero.

Las dudas son reforzadas por el hecho de que la única otra mención que en toda la rhesis se hace de la visión del mensajero se produce en el v. 1077 (к $\alpha i$

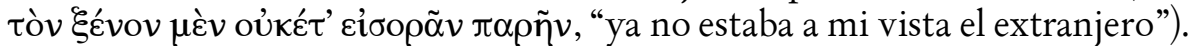
Nuevamente la afirmación de la visión se refiere a algo que sucede en el grupo de personajes que realiza la expedición al Citerón, un grupo del que el mensajero forma parte y cuya visión se asume como necesaria y obvia, pero la visión del mensajero no llega a afirmarse para nada relativo a lo que sucede en el escenario en el que se encuentran las bacantes.

Por otra parte, en esa segunda alusión a su visión, o, mejor dicho, a su ausencia de visión, el mensajero deja constancia de la desaparición del extranjero, un hecho que va seguido (vv. 1078 ss.) de la descripción de cómo se escucha una voz, que él interpreta como la voz de Dioniso. El espectador, conocedor de la identidad de Dioniso desde el prólogo, entiende la desaparición del extranjero como señal de la epifanía ${ }^{31}$ e identifica obviamente al extranjero con Dioniso. Pero el Coro y el propio mensajero no entienden la relación entre Dioniso y el extranjero ${ }^{32}$. Así, la no visión del extranjero tiene un significado para la audiencia externa que no tiene ni para el emisor (el mensajero), ni para la audiencia interna (el Coro de ménades lidias), que siguen creyendo que el extranjero y Dioniso son seres diferentes. De hecho, ninguno de los personajes que participan en la obra comprende al final de la tragedia la identidad real del extranjero. Centrando de nuevo la cuestión en el mensajero, este hecho deja claro que el ä $\gamma \gamma \varepsilon \lambda$ os es capaz sólo de una

${ }^{29}$ La descripción del modo en que se curva el árbol para que Penteo pueda subir en él incluye un símil, que ha generado una amplia discusión. Al respecto, cf. M. Stieber, "The Wheel Simile in Bacchae, another Turn”, Mnemosyne 59, 2006, 585-92.

${ }^{30}$ En la escena del 'milagro del palacio' los mismos hechos son percibidos de manera opuesta por el Coro y por Penteo. Esto se debe a que la interpretación de la realidad es subjetiva y depende en gran medida de las distintas creencias que se manejan. Al respecto, cf. Encinas Reguero, "Bacantes de Eurípides".

${ }^{31} \mathrm{La}$ epifanía de un dios se caracteriza normalmente por la aparición de dicho dios. En Bacantes, en cambio, irónicamente la epifanía del dios se caracteriza por su desaparición, lo que se aprecia tanto en este relato del mensajero como anteriormente, en la escena del 'milagro del palacio' (vv. 576 ss.).

${ }^{32}$ Tanto el Coro de ménades lidias (en la escena del 'milagro del palacio'), como las bacantes del Citerón (en este relato de mensajero) se enfrentan a sendas epifanías, caracterizadas curiosamente por la desaparición del dios y la posibilidad de escuchar sólo su voz. En ambos casos las bacantes reconocen al dios cuando desaparece y dejan de reconocerlo cuando lo tienen presente. La problematización de la visión es, sin duda, una cuestión esencial en Bacantes. 
comprensión parcial y subjetiva de la realidad que percibe, lo que tácitamente apunta de alguna manera a un cuestionamiento de su relato.

Tras la orden de Dioniso, dos veces repetida, comienza el ataque a Penteo, que se prolonga hasta conseguir derribarlo del árbol ${ }^{33}$. El modo en que se presentan los hechos incide en el problema expuesto.

Como ha quedado dicho, en la descripción inicial de las bacantes el mensajero no afirma explícitamente su visión (aunque las describe con detalle, lo que parece implicar que las ve), pero sí afirma la no-visión de Penteo, al que él acompaña. Esta situación resulta problemática, porque, si ambos están juntos, no se entiende por qué uno puede ver a las bacantes y el otro no. Pues bien, cuando comienza el ataque contra Penteo, el mensajero describe a las bacantes a la carrera y dice que "A saltos traspasaron los torrentes del valle, y escalaban las escarpadas peñas enloquecidas por los influjos del dios.

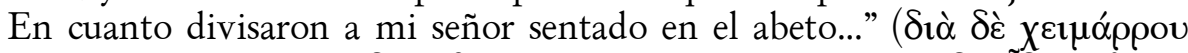

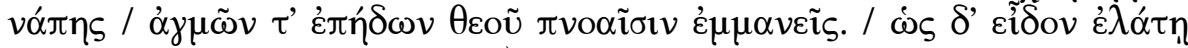

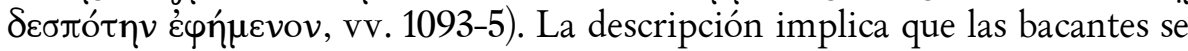
encontraban a una distancia considerable, aparentemente fuera del campo de visión del grupo de Penteo. Y si ellas desde donde estaban no podían ver a Penteo, ni siquiera subido al árbol, es lógico pensar que tampoco para Penteo era fácil verlas a ellas y que subir al árbol para tratar de tener una visión más amplia era necesario. Cobran, por tanto, sentido las palabras del rey en la parte primera de la narración ${ }^{34}$. Pero si realmente Penteo no podía ver a las bacantes desde donde se encontraba, entonces la visión que queda cuestionada es la del mensajero en el primer apartado de la narración.

Puesto que dentro de las convenciones trágicas el mensajero es tradicionalmente un testigo presencial que ofrece un relato fiable de lo que ha visto, lo natural inicialmente, cuando se produce la situación en la que un mensajero y Penteo están juntos pero ven algo muy diferente, es cuestionar la visión de Penteo, que, además, ha sido puesta en tela de juicio anteriormente ${ }^{35}$.

33 Según A. F. H. Bierl, Dionysos und die griechische Tragödie. Politische und 'metatheatralische'Aspekte im Text, Tübingen 1991, 213, la caída el árbol muestra visualmente el cambio de status en Penteo, que pasa de espectador a actor.

${ }^{34}$ Se podría pensar que al subir al árbol Penteo finalmente consigue visualizar a las bacantes, pero Eurípides cuidadosamente niega este hecho. Después de describir cómo el extranjero curva el árbol para que Penteo se encarame en él y lo yergue nuevamente hasta que queda firme,

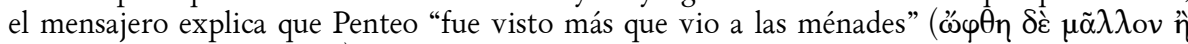
$\kappa \alpha \tau \varepsilon \tilde{\delta} \delta \varepsilon \mu \alpha \imath v \alpha ́ \delta \alpha \varsigma$, v. 1075), con lo que incluso en este momento le niega al rey la visión.

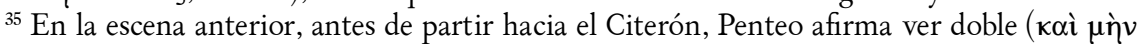

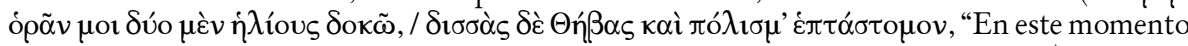
me parece ver dos soles, y una doble ciudad de Tebas, con sus siete puertas”, vv. 918-9) y dice ver

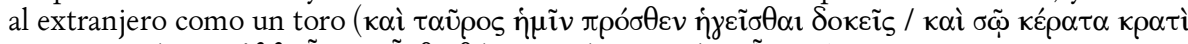

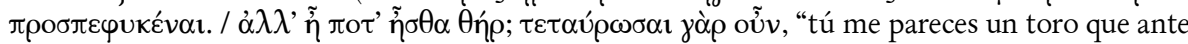
mí me guía y que sobre tu cabeza han crecido cuernos. ¿Es que ya eras antes una fiera? Desde luego estás convertido en toro", vv. 920-2). Según R. Seaford, "Pentheus' Vision: Bacchae 91822”, CQ 37, 1987, 76-8, la doble visión de Penteo en este pasaje se puede explicar por el uso de 
No obstante, al avanzar el relato, el espectador tiene que replantearse la situación y cuestionar también la visión del mensajero ${ }^{36}$. Este proceso conduce a una reflexión más amplia: el espectador no duda inicialmente de la visión del mensajero, aunque ésta no se afirma explícitamente, porque se deja llevar por las convenciones trágicas que conoce y asume. Es decir, la propia comprensión o recepción del espectador se ve alterada inconscientemente por lo que cree saber y así, en último término queda también cuestionada. La situación expuesta deja claro, de un lado, que la visión de todo personaje, incluido el mensajero, está sometida a sus propias creencias y, por tanto, no puede ser completamente objetiva, $y$, por otro lado, que, al igual que sucede con los personajes, también la propia visión y comprensión del espectador depende de cuestiones subjetivas (como la aceptación de unas convenciones en el teatro).

A través del énfasis puesto en la visión en el primer relato de mensajero, Eurípides insinúa la necesidad de prestar atención a esta cuestión en el segundo, compuesto de manera paralela. En ese segundo relato de mensajero se presenta a dos personajes, que, enfrentados a la misma realidad, la experimentan y transmiten de un modo completamente diferente. Es, en cierto modo, una nueva versión de la escena del 'milagro del palacio'. Y, como en esa escena, también en el relato de mensajero el conflicto entre dos versiones diferentes de una misma realidad es utilizado al servicio de un significado más amplio y mucho más complejo, pues con esas escenas Eurípides parece querer instar al espectador a mirar más allá de lo aparente y más allá incluso de las convenciones o normas asumidas ${ }^{37}$.

un espejo, elemento utilizado en los misterios dionisíacos para confundir al iniciando. Respecto a la identificación del dios con un toro, es importante señalar que no es la primera vez que se produce. Recuérdese que en la escena del 'milagro del palacio' Penteo confunde al extranjero precisamente con ese animal (vv. 618 ss.). Por otra parte, la visión de Penteo es cuestionada a lo largo de toda la obra también por no ser capaz de apreciar las señales que se le ofrecen de la divinidad de Dioniso. Al respecto J. Gregory, "Some Aspects of Seeing in Euripides' Bacchae", $G \& R 32,1985,28$, afirma que "The audience is thus invited to recognize that autopsy, contrary to general belief, is not infallible: men see, in fact, only what they are predisposed to see".

${ }^{36}$ J. I. González Merino, "Los $\theta \alpha u ́ \mu \alpha \tau \alpha$ de las ménades (Bacantes 677-774)”, en J. Peláez, ed., El dios que hechiza y encanta. Magia y astrología en el mundo clásico y helenístico. Actas del I congreso nacional, Córdoba 1998, Córdoba 2002, 133-42, cuestiona incluso la visión del primer mensajero. Él analiza todo el primer relato de mensajero defendiendo que se trata de una mezcla de exageración y fantasía. Por ejemplo, lo primero que ese mensajero dice es que llega a Tebas desde el Citerón, donde jamás se quita la nieve (vv. 660-2). No obstante, hablar de nieves perpetuas en el Citerón causaría sorpresa y parecería una exageración. Este autor (González Merino, “Los $\theta \alpha u ́ \mu \alpha \tau \alpha ”, 135)$ considera que estas primeras palabras del boyero son ya un aviso de que no es un personaje fiable.

${ }_{37}$ T. G. Rosenmeyer, "Tragedy and Religion: the Bacchae", en E. Segal, ed., Oxford Readings in Greek Tragedy, Oxford 1983, 371-2, considera Bacantes como una precursora de los diálogos platónicos, porque conduce al receptor a reconsiderar su modo de pensar y sus valores. 


\section{LA VISIÓN DE LAS BACANTES}

Además de la visión del mensajero y Penteo, en el segundo relato de mensajero entra en juego una nueva visión, la de las bacantes. El mensajero, Penteo y las bacantes representan todos ellos actitudes diferentes con respecto al dios y tienen diferentes tipos de visión. Penteo se opone por completo a reconocer el poder del dios y es castigado por ello; él intenta ver, pero, como se señala enfáticamente en el relato de mensajero, no lo consigue. El mensajero cree en el dios y en sus milagros; él sí consigue ver aquello que pretende, aunque su visión ha de ser cuestionada, según se desprende de lo dicho en el apartado anterior. Las bacantes son seguidoras del dios, pero lejos de hacerlo de manera voluntaria, como las ménades lidias, lo siguen forzosamente; su visión de la realidad, como se verá a continuación, está completamente sometida al dios ${ }^{38}$.

La primera referencia a la visión de las bacantes es implícita y se produce cuando el mensajero explica que Penteo, tras subirse al árbol, fue visto ( $ڤ \varrho \varphi \eta \eta$

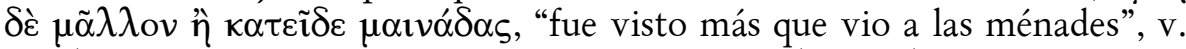
1075). El objetivo del soberano era ver sin ser visto (v. 1050); lo que consigue, sin embargo, es exactamente lo contrario, ser visto sin ver (v. 1075). La segunda referencia a la visión de las bacantes se halla en el v. 1095 ( $\dot{\omega} \varsigma$ $\delta$ ' $\varepsilon \tilde{i} \delta o v$

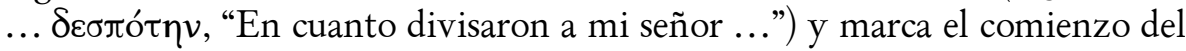
ataque. Pero aquí surge una cuestión interesante: Penteo se ha disfrazado de mujer precisamente para no suscitar recelos entre las bacantes; sin embargo, éstas lo atacan sin reparar en sus vestiduras.

En el primer discurso de mensajero se dice que el peligro para las bacantes

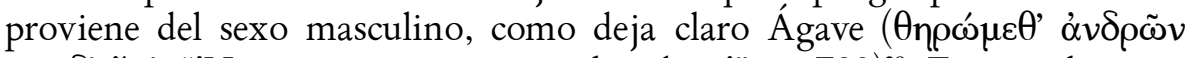
$\tau \tilde{\omega} \nu \delta$ ' $̈ \pi$ ', “iNos quieren cazar estos hombres!”, v. 732) $)^{39}$. Esto explica que Dioniso sugiera a Penteo que se vista de mujer ${ }^{40}$. El argumento que esgrime el dios es precisamente el riesgo que supone para el monarca su condición de

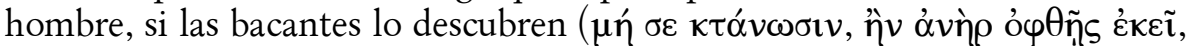
"Para que no te maten, si te descubren como hombre", v. 823) ${ }^{41}$. Dada la

${ }^{38}$ Gregory, "Some Aspects of Seeing", 28-9, ofrece varios ejemplos en esta tragedia de la visión divergente de quien cree y quien no lo hace.

${ }^{39}$ En las palabras de Ágave se refleja la idea de la caza, tan importante en la tragedia (cada vez más importante a medida que avanza la obra). Sobre la representación del mundo animal así como sobre el tema de la caza, cf. C. Thumiger, "Animal World, Animal Representation, and the 'Hunting-Model': between Literal and Figurative in Euripides' Bacchae", Phoenix 60, 2006, 191-210.

${ }^{40}$ Según R. Seaford, “Dionysiac Drama and the Dionysiac Mysteries”, CQ 31, 1981, 258-9, el travestismo de Penteo no sirve a ningún propósito dentro de la acción de la obra. Seaford relaciona el travestismo con los rituales de iniciación en Grecia, cuya función pasa por privar al iniciando de su identidad previa para que pueda asumir una nueva.

${ }^{41}$ En ésta y otras escenas se puede apreciar la manera en que Dioniso dirige y organiza la acción. Esta función de Dioniso en Bacantes ha sido comparada con la que tiene Agatón en Tesmoforiantes y esa similitud es, de hecho, uno de los puntos de unión entre esas dos obras 
situación expuesta en el primer relato, esta argumentación parece lógica. Sin embargo, en el segundo relato de mensajero los hechos se desarrollan de un modo muy curioso.

Efectivamente, Penteo se viste de mujer y sube a un árbol ${ }^{42}$. Las bacantes, instigadas por el dios, lo descubren allí encaramado. Las palabras del dios (' $\Omega$

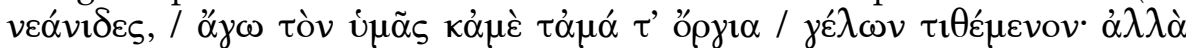
$\tau \iota \mu \omega \rho \varepsilon \tilde{\sigma} \sigma \theta \dot{\varepsilon} v ı v$, "iAh, jóvenes mujeres, os traigo al que intenta burlarse de vosotras y de mis ritos! iCastigadle ahora en venganza!", vv. 1079-81) no

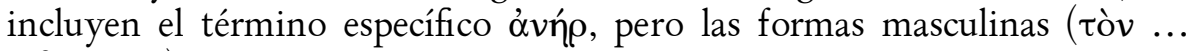
$\tau \imath \theta \varepsilon ́ \mu \varepsilon v o v)$ no parecen dejar duda respecto a la condición sexual del 'espía'. No obstante, dado que Penteo está travestido, existe una inconsistencia entre lo que las bacantes ven (una figura aparentemente femenina) y lo que oyen en las palabras del dios (formas gramaticales masculinas). Pues bien, esto último se impone. Las bacantes se dejan llevar ciegamente por la orden del dios, sin que lo que tienen ante sus ojos las haga dudar ni por un instante.

Más adelante, cuando Ágave insta al ataque al resto de bacantes, identifica

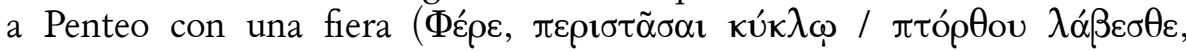

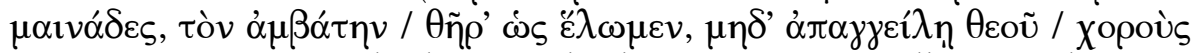
кpuyaíous, "Venga, rodead en círculo el tronco, y arrancadlo, ménades, para que atrapemos a la fiera encaramada, que no pueda divulgar las secretas danzas en honor del dios”, vv. 1106-9). Este término (Өń $\rho)$ también es masculino, así que encaja dentro de las palabras del dios. No obstante, las fieras celebran

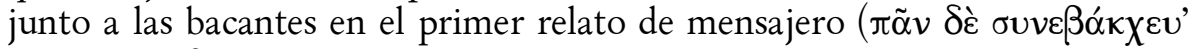
ópos / kaì $\theta \tilde{n} \rho \varepsilon \varsigma$, "El monte entero y sus animales salvajes celebraban con ellas", vv. 726-7) y las bacantes no perciben peligro por su parte; de hecho, las

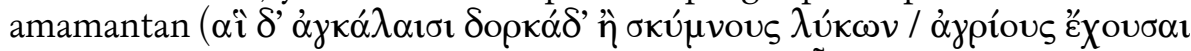

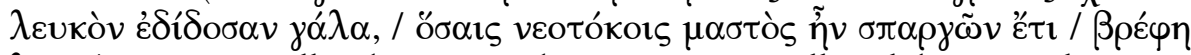

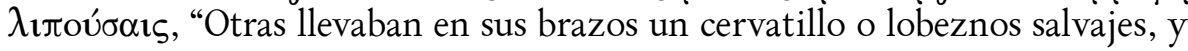
les daban su blanca leche todas aquellas que de un reciente parto tenían aún el pecho rebosante y habían abandonado a sus recién nacidos”, vv. 699-702). ¿Por qué, entonces, en el segundo relato de mensajero se las considera un peligro? ${ }^{43}$.

dramáticas que señalan quienes defienden una relación directa entre ellas. Sobre la posibilidad de considerar Bacantes como una respuesta a Tesmoforiantes cf. R. Saetta Cottone, "Penteo spettatore di tragedia: le Baccanti e la risposta alle Tesmoforiazuse", Argos 31, 2007, 43-65. Véase también V. Di Benedetto, Euripide. Le Baccanti, Milano 2004, 41-3.

42 Por supuesto, no ha faltado quien ha interpretado esta escena sexualmente desde un punto de vista psicoanalítico. Al respecto, cf. W. Sale, "The Psychoanalysis of Pentheus in the Bacchae of Euripides", YCS 22, 1972, 73-4. Por su parte, C. M. Kalke, "The Making of a Thyrsus: the Transformation of Pentheus in Euripides' Bacchae", AJPh 106, 1985, 417, cree que el árbol con Penteo encaramado en su copa puede ser símbolo de una erección, pero no de Penteo, sino del dios, y de su poder, al igual que los falos portados en las procesiones dionisiacas como símbolo del poder de fertilidad de este dios.

${ }^{43}$ En el primer relato las bacantes toman a las bestias por seres humanos; primero, 
Ágave argumenta que hay que dar caza a la fiera (Penteo) para evitar que divulgue los secretos del dios (vv. 1108-9). Ahora bien, ¿cómo podría una fiera comunicar algo ${ }^{44}$. Ágave y el resto de bacantes no ven lo que tienen delante (aparentemente una mujer), ni tampoco se guían por la razón (el hecho de que una fiera no puede desvelar sus secretos). Ojos y razón las engañan. Ellas se dejan llevar ciegamente por las palabras del dios. En ese sentido, las bacantes, sometidas a la voluntad de Dioniso, se comportan como una manada irracional ${ }^{45}$.

Ágave es la primera en atacar a Penteo y echarse sobre él ${ }^{46}$. En ese momento Penteo se quita sus adornos femeninos para mostrar su verdadera identidad, al

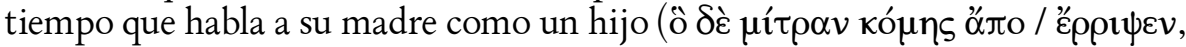

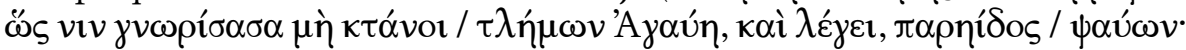

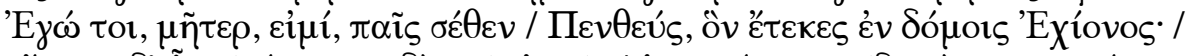

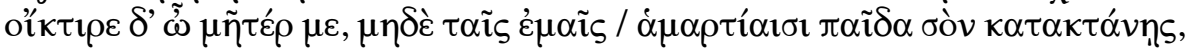
"Penteo se arrancó la diadema del cabello para que le conociera y no lo matara la infeliz Ágave. Al mismo tiempo decía, acariciando su mejilla: 'iSoy yo, madre mía, yo, tu hijo! iPenteo, al que diste a luz en la morada de Equino! iTen piedad de mí, madre, y no vayas a matar, por culpa de mis errores, a tu propio hijo!", vv. 1115-21). Ser visto y reconocido es irónicamente su única esperanza

al amamantarlas y después al vengarse de los pastores en sus rebaños. En el segundo relato, en cambio, toman al hombre por una bestia, cuando confunden a Penteo con un león; cf. Winnington-Ingram, Euripides and Dionysus, 96.

${ }^{44}$ Winnington-Ingram, Euripides and Dionysus, 130-1, advierte la paradoja de que Ágave perciba a Penteo simultáneamente como animal y como espía humano. Él considera que esta confusión es utilizada para poner en evidencia el estado mental en el que se encuentra Ágave. En esa misma línea, Jong, "Récit et Drame”, 580-1, explica esa contradicción argumentando que Ágave ve doble, lo cual es una característica del furor dionisíaco.

${ }^{45}$ Los efectos nefastos de tener un comportamiento ciego e irracional quedan ejemplificados por las bacantes y por el daño que provocan, que afecta a toda la sociedad. De hecho, M. Hose, Drama und Gesellschaft. Studien zur dramatischen Produktion in Athen am Ende des 5. Jahrhunderts, Stuttgart 1995, 168, ve la obra como una llamada de atención sobre los peligros de una masa influenciable e influenciada y en ese sentido se puede decir que Bacantes representa la problemática de su época. Para este autor, la obra no se limita a exponer los problemas ligados a un nuevo dios y su culto, sino que muestra al hombre desde una nueva perspectiva; cf. M. Hose, Euripides. Der Dichter der Leidenschaften, München 2008, 2189. Por su parte, M. Arthur, "The Choral Odes of the Bacchae of Euripides", YCS 22, 1972, 169-70, compara Bacantes con la Orestía de Esquilo y explica que, si esta última es una glorificación de la estructura legal y política de la polis y también del poder de la ley ateniense para contener las fuerzas destructivas y caóticas del mundo, Bacantes trata el proceso inverso, esto es, el modo en que las fuerzas instintivas y primitivas acaban con la estructura legal y social y provocan la caída de la polis.

${ }^{46}$ Foley, Ritual Irony, 206, pone de relieve el hecho de que el desastre trágico de Penteo se representa como un sacrificio pervertido. En su opinión, "the ritual crisis reflects a fundamental disruption in the relation between man and god and among men in the community". De hecho, el acto de cazar y comer carne cruda en las montañas reemplaza el sacrificio de animales domésticos dentro de la ciudad; cf. C. Segal, "Euripides' Bacchae: Conflict and Mediation", Ramus 6, 1977, 111. 
de salvación. Pero, poseída por el dios, Ágave no es capaz de razonar ni de

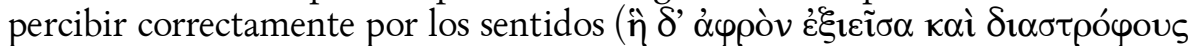

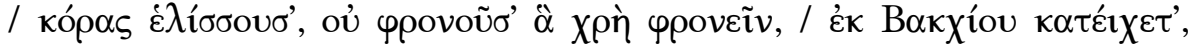
"ella echaba espuma de la boca y revolvía sus pupilas en pleno desvarío, sin pensar lo que hay que pensar. Estaba poseída por Baco", vv. 1122-4). Penteo es despedazado y Agave es la principal responsable de ello ${ }^{47}$.

Sugestionadas por Dioniso, las bacantes, y Ágave entre ellas, obedecen las palabras del dios, que anula o trastorna por completo su visión ${ }^{48}$. Y puesto que el dios que domina a las bacantes, Dioniso, es también el dios del teatro y, por lo tanto, en cierto modo controla el espectáculo que la audiencia contempla, las posibilidades de una interpretación metateatral surgen inexorablemente ${ }^{49}$.

\section{CONCLUSIÓN}

Tradicionalmente ver algo es señal irrefutable de su conocimiento. De ahí la fuerza que el $\mu \alpha \rho \tau$ úpiov o testimonio (de un testigo presencial de los hechos, se entiende) tiene como prueba y de ahí también en gran medida la autoridad dentro de la tragedia griega del relato de mensajero, transmitido según las convenciones de la escena griega, por un testigo presencial de los hechos narrados $^{50}$. Sin embargo, en Bacantes la visión es seriamente cuestionada y problematizada.

Para empezar, Dioniso en esa obra no se revela mostrándose, sino que se revela, sobre todo, haciéndose oír. De hecho, los dos momentos de epifanía

${ }^{47}$ El paso de Penteo de cazador a cazado, así como la terrible descripción de su desmembramiento, ayudan a crear una inversión en la simpatía de la audiencia, que finalmente se dirige al monarca. Sobre la inversión de la simpatía de la audiencia respecto a Penteo, cf. J. E. G. Whitehorne, "The Dead as Spectacle in Euripides' Bacchae and Supplices", Hermes 114, 1986, 64-5.

${ }^{48}$ Hose, Drama und Gesellschaft, 168, cree que con el comportamiento irracional de las bacantes Eurípides puede aludir implícitamente al pueblo ateniense. En relación con esto es interesante poner de relieve que, cuando finalmente Ágave en la exodos recupera la cordura, lo hace tan solo después de separarse del resto de bacantes; cf. Winnington-Ingram, Euripides and Dionysus, 132.

${ }^{49} \mathrm{La}$ interpretación metateatral de Bacantes surge del hecho de que Dioniso es el centro de la obra y al mismo tiempo el dios del teatro. Cf., por ejemplo, Segal, Dionysiac Poetics, 215-271, C. Segal, "The Bacchae as Metatragedy", en P. Burian, ed., Directions in Euripidean Criticism. A Collection of Essays, Durham 1985, 156-73, Bierl, Dionysos und die griechische Tragödie, 186-218 o G. Radke, Tragik und Metatragik, Berlin 2003. Sin embargo, autores como W. Kullmann, "Die 'Rolle' des euripideischen Pentheus. Haben die Bakchen eine 'metatheatralische' Bedeutung?”, en G. W. Most, H. Petersmann, A. M. Ritter, eds., Philanthropia kai Eusebeia. Festschrift für Albrecht Dihle zum 70. Geburtstag, Göttingen 1993, 248-63, se oponen a la interpretación metateatral de este drama. Sobre las alusiones al teatro en los dos relatos de mensajero, así como en otros momentos de la tragedia; cf. Foley, Ritual Irony, 215-34.

${ }^{50}$ La relación entre ver y saber o conocer se percibe perfectamente en la relación entre las formas عĩ்ov y oĩ $\delta \alpha$. Sobre la relevancia del ojo y de la visión en el mundo antiguo, cf. Rizzini, "Le Baccanti", 109-24. 
que se producen en la obra ante la audiencia interna, uno directamente en escena ante el Coro de ménades lidias (el 'milagro del palacio') y el otro de manera narrada y ante el Coro de bacantes tebanas (en el segundo relato de mensajero), se caracterizan curiosamente por la desaparición del dios y la posibilidad de escuchar sólo su voz ${ }^{51}$. Únicamente cuando el dios es oído, y no visto, es reconocido como tal, mientras que en los momentos en que es visto es identificado con el extranjero y no reconocido. La visión de los hechos, por tanto, queda en esta obra fuertemente cuestionada.

Pero la problematización de la visión se desarrolla en Bacantes de muchas maneras y a lo largo de todo su transcurso ${ }^{52}$. Lugar destacado ocupa en esa problematización de la visión la llamada escena del 'milagro del palacio', tantas veces discutida ${ }^{53}$. Y también es importante en ese sentido el papel que juegan los dos relatos de mensajero.

Los dos relatos de mensajero de Bacantes (vv. 677-774 y 1043-152) son peculiares, entre otras cosas, porque están compuestos de forma paralela. Ese paralelismo estructural y temático entre los dos relatos conduce a detenerse en las diferencias que se dan entre ambos, y una de ellas, probablemente la más significativa, es la manera en que se presenta la visión de los hechos. En el primer relato se enfatiza la cualidad de testigo presencial del mensajero y se apunta reiteradamente a la visión que habría tenido Penteo de haber estado presente en el Citerón. Es decir, la importancia que la acción de 'ver' adquiere en el primer relato de mensajero dirige la atención también a esta cuestión en el segundo relato. Ahí son tres los tipos de visión que se encuentran y esos tres tipos de visión reflejan tres modos diferentes de relación con el dios. Penteo, que niega al dios, simplemente no puede ver; el mensajero, que acepta al dios, ve o cree ver (el relato no deja claro si es lo uno o lo otro); y las bacantes, dominadas por el dios, tienen una visión deformada de la realidad y sometida por completo a la voluntad de Dioniso.

Ese amplio cuestionamiento de la visión, y consecuentemente de la transmisión de la información obtenida a partir de la visión, conduce a una reflexión más profunda en relación con la aceptación de lo establecido y, por tanto, impulsa una actividad de crítica en la audiencia ante todo lo percibido, incluido el espectáculo teatral. El espíritu de esta obra se aproxima así, como se ha dicho en alguna ocasión ${ }^{54}$, al de los diálogos platónicos.

Muchas veces se ha considerado Bacantes como una tragedia tradicional por su temática, estilo y estructura. Sin embargo, lo cierto es que lo tradicional está utilizado en esta obra con un espíritu e intención completamente nuevos

\footnotetext{
${ }^{51}$ No es irrelevante tampoco el hecho de que Tiresias, el personaje de la ciudad que más dispuesto está a acoger y defender al dios, es ciego.

${ }^{52}$ Cf. Thumiger, "Visione e identità", Rizzini, "Le Baccanti".

${ }^{53}$ Cf. Encinas Reguero, "Bacantes de Eurípides".

${ }^{54} \mathrm{Cf}$. nota 37.
} 
y es eso lo que permite decir que Bacantes es una obra innovadora y en sintonía con el pensamiento de su época. 
